\title{
A EDUCAÇÃO EM DIREITOS HUMANOS E AS NOVAS TECNOLOGIAS PARA O EXERCÍCIO DA CIDADANIA
}

\author{
EDUCATION IN HUMAN RIGHTS AND NEW TECHNOLOGIES FOR THE \\ CITIZENSHIP EXERCISE
}

\begin{abstract}
Mônica de Freitas Soares
Professora II. Ensino Fundamental/Secretária Escolar da Prefeitura Municipal de Nova Iguaçu/ SEMED. Secretaria de Educação. Pós graduação em Letras Vernáculas literatura Infanto Juvenil (UFRJ) e Direito Público (Dir. Constitucional, Tributário e Administrativo) (Estácio). https://orcid.org/0000-0002-7540-2923

Verônica Eloi de Almeida

Doutora em Sociologia - Núcleo de Pesquisa em Sociologia da Cultura - UFRJ/IFCS. Pesquisadora do Mestrado em novas tecnologias digitais na educação - UNICARIOCA

https://orcid.org/0000-0003-4694-8617

Data de submissão: 05/05/2020

Data de aprovação: 30/05/2020
\end{abstract}

\section{RESUMO}

A presente pesquisa, de base bibliográfica, tem como finalidade chamar à reflexão questões relacionadas à educação em direitos humanos a partir do uso das novas tecnologias digitais. Apesar da existência de leis, que regulam os direitos humanos, a educação em direitos humanos poderia ser mais discutida no espaço escolar, e por outro lado, pouco se capacitam profissionais para aderir à educação em direitos humanos. $O$ uso das tecnologias digitais pode ser um aliado rumo a uma educação mais inclusiva e que respeite o multiculturalismo.

Palavras-chave: Educação. Direitos humanos. Novas tecnologias.

\section{ABSTRACT}

The present research, with bibliographic base, aims to call to reflection issues related to human rights education from the use of new digital technologies. Despite the existence of laws, which regulate human rights, human rights education could be more discussed in the school environment, and on the other hand, little professionals are trained to adhere to human rights education. The use of digital technologies can be an ally towards a more inclusive education that respects multiculturalism.

Keywords: Education. Human rights. New technologies.

\section{INTRODUÇÃO}

A conquista da cidadania e a efetividade dos direitos fundamentais à vida humana, em suas diversas dimensões, têm enfrentado muitas discussões e lutas ao longo das décadas, principalmente com o advento da globalização em que a abrangência do sentido de cidadania se perde diante das muitas realidades econômicas, sociais e políticas existentes.

A reflexão sobre os Direitos Humanos tornou-se mais contundente após o efeito devastador da Primeira Guerra Mundial, pelo número de mortes cruéis, pelo 
genocídio e desrespeito ao homem que, porventura, viesse a ser capturado sem meios de defesa e cativo pela força inimiga, conforme menciona a Enciclopédia do Holocausto (2020).

A Primeira Guerra Mundial foi uma das guerras mais destrutivas da história moderna. Quase dez milhões de soldados morreram como resultado das lutas, um número que excedeu, em muito, as perdas militares de todas as guerras dos cem anos anteriores em conjunto. Embora seja difícil fazer uma estimativa precisa do número de baixas, calcula-se que aproximadamente 21 milhões de homens foram feridos em combate. $\mathrm{O}$ grande número de perdas para todos os participantes do conflito deveu-se, em parte, à introdução de novos armamentos, como a metralhadora e o emprego de gás, e também à incapacidade dos líderes militares de ajustarem suas táticas à natureza cada vez mais mecanizada da guerra.

A história, assim, remonta à trágica noção que tinham os homens sobre o respeito ao indivíduo como ser dotado de direitos humanamente pensados. Em 1948, foi criada a Declaração Universal dos Direitos Humanos, como reação às atrocidades cometidas durante a Segunda Guerra Mundial, quando Hitler ordenou o genocídio de judeus e de outras minorias étnicas. A Declaração Universal dos Direitos Humanos (1948) foi importante para ratificar e nortear direitos humanos, que não devem ser relativizados nem em ocasiões de guerra. Os direitos humanos consistem em uma importante ferramenta de proteção a qualquer cidadão no mundo, e funcionam como uma garantia contra as situações de abuso, intolerância, opressão e discriminação (SOUZA, 2017).

No contexto histórico sobre Direitos humanos, o Brasil se faz presente quando, como Estado Internacional, aderiu aos Tratados e convenções e os Estados internos foram conclamados a incorporar em suas políticas públicas a proteção aos direitos humanos. A adesão do Brasil ao Estatuto de Roma em 1998 e a ratificação pelo ordenamento jurídico interno, assim expresso no art. 5ำ $§ 3^{\circ}$ da Constituição Federal de 1988, pela emenda Constitucional número 45 de 2004, foram fundamentais no sentido de se estabelecer o respeito aos direitos humanos (BRASIL, 1988).

Nesse sentido, com a Constituição brasileira (BRASIL, 1988), há maior ênfase em se proteger a todos os seres humanos, aos que chegam e permanecem no país, aos suscetíveis de ameaças e aos que se mostram frágeis diante dos excessos de intolerância. O Estado pode lançar mão de organismos que levam à punição dos que tentam infringir a lei, com base no Decreto e nas leis que normatiza. O Estatuto de Roma (BRASIL, 2002) em seu preâmbulo assim, afirma:

[...] os crimes de maior gravidade, que afetam a comunidade internacional no seu conjunto, não devem ficar impunes e que a sua repressão deve ser efetivamente assegurada através da adoção de medidas em nível nacional e do reforço da cooperação internacional.

A Constituição brasileira (BRASIL, 1988) trouxe normas fundamentais que fomentam relações mais humanizadoras, introduzindo a discussão sobre os direitos humanos em diversos âmbitos sociais. A expectativa era estabelecer a dimensão sobre 0 estado democrático de direito apoiado principalmente nos direitos fundamentais e na dignidade da pessoa humana. Para tanto, em 1997, os Parâmetros Curriculares Nacionais (PCN) propuseram que as escolas trabalhassem os Temas Transversais nas séries iniciais implementando:

[...] uma educação comprometida com a cidadania, baseados no texto constitucional, princípios segundo os quais orientar a educação escolar: Dignidade da pessoa humana, respeito aos direitos humanos, repúdio à discriminação de qualquer tipo, acesso a condições de vida digna, respeito mútuo nas relações interpessoais, públicas e privadas. (BRASII, 1997, p. 20). 
O esforço em tratar dos direitos humanos como prática educativa, nesses moldes, seria uma primeira aproximação ao tema, comportando uma reflexão aos princípios éticos e humanos no contexto escolar (BRASIL, 1997). Mais tarde, o Plano Nacional de Direitos Humanos (PNEDH, 2007) foi lançado. Discutido e elaborado pelo Comitê Nacional de Educação em Direitos Humanos (CNEDH), o Plano contém diretrizes principiológicas que fomentam o engajamento em projetos de incentivo à Educação Básica em Direitos Humanos.

Diante disso, a escola não pode se dar por isenta da responsabilidade em explorar o tema dos direitos humanos, visto que pode ser um dos loci mais propícios para a prática da democracia, pois na escola se abrem caminhos para discussão criativa que pode levar os indivíduos a ter discernimento sobre direitos e respeito. Logo, o investimento no espaço escolar propicia aos seus componentes a troca de experiências, pois através dela é possível estabelecer a valorização de cada vivência e permitir que todos - professor, aluno e os demais atores - compartilhem os conhecimentos que emanam de suas diferenças.

De posse desse entendimento, a escola se torna uma via mediadora para diminuir o abismo entre aqueles que possuem um status econômico elevado e aqueles que conseguem, com toda a precariedade, ingressar no ensino e se formar. Embora haja políticas públicas educacionais para aumentar o acesso à escolarização no Brasil há algumas décadas, as escolas são muito heterogêneas em se tratando de qualidade (PAIVA, 2010). Logicamente, nesse processo, muitos princípios constitucionais fundamentais à pessoa são violados, principalmente no tocante à igualdade.

Mesmo assim, Carvalho (2006, p. 24-25) ressalta que a escola deve buscar viabilizar práticas que potencializem a reflexão sobre valores e questões mais humanizadoras, que levem os indivíduos a entender os parâmetros e diretrizes conceituais dos direitos humanos e da democracia, de modo que fique:

[...] cada vez mais patente a necessidade de que a formação de professores integre de forma crescente os aportes teóricos gerais (por exemplo, (a partir de discussões da filosofia, sociologia, do direito etc.), as reflexões mais estritamente educacionais e escolares (como os efeitos da violência ou da mídia nas escolas) e a apresentação e discussão de obras clássicas da cultura (como filmes, peças, poemas etc.) nos quais os temas em pautas sejam focalizados não em sua dimensão abstrata ou conceitual, mas em representações de vivências pessoais. A leitura analógica que estas obras permitem - por oposição à analítica exigida pelas primeiras - parece ter uma capacidade muito maior de promover a identificação com valores.

Então, considerando a análise do autor, a escola tem como papel fundamental o preparo dos seus indivíduos e de suas consciências relativas às questões humanas, porque não se pode ignorar o fato de que hoje, necessariamente, deve-se olhar as diferenças como promoção do respeito aos direitos humanos.

\section{REFERENCIAL TEÓRICO}

\subsection{Direitos Humanos na Escola}

As tecnologias digitais são uma nova forma de as pessoas manterem-se conectadas em suas vidas cotidianas. Além disso, propiciam um novo formato ao espaço urbano, adentrando diversos espaços, como por exemplo, a escola. O compartilhamento de ideias na escola deve ser construído por meio das vivências sociais e seus atores, muitas vezes, navegam no mundo das mídias, e adentram esse universo de modo que suas ações são interligadas aos mecanismos digitais e neles se constroem (VILAÇA; ARAUJO, 2016).

Por outro lado, é nítida a falta de estrutura, de espaço, bem como de aporte relativo à capacitação teórica e prática sobre o ensino tecnológico dos professores e de seus alunos 
nas escolas públicas. No entanto, é necessário observar a inclusão digital como um direito humano (PADILHA, 2018).

Para Padilha (2018, p. 192) "usar tecnologia na sala de aula hoje não é mais opção para o professor ou para a escola. Os alunos precisam ter acesso às diversas linguagens, inclusive e, principalmente, as digitais, pois vivem em um mundo digital". Ressalta-se ainda que a inserção no mundo digital requer um compromisso na formação com a criticidade e a consciência criativa. Segundo Silva (2013, p.840-841):

Trata-se de uma responsabilidade para com as novas gerações, principalmente caso se leve em consideração o fato de que muitos não compreendem o que é a tecnologia e qual o lugar que ela deve ocupar na vida dos seres humanos. [...] não se trata apenas de desenvolvê-la a qualquer custo, mas de levantar a questão sobre o sentido desse desenvolvimento. É um debate que envolve, também, saber as vantagens e desvantagens do desenvolvimento tecnológico. Por um lado, percebese os enormes e fundamentais benefícios provocados por ele, o qual tem sido vertiginoso nos últimos anos; por outro, não se pode negar o surgimento de problemas relacionados a esse desenvolvimento.

É, portanto, possível pensar em uma escola conectada com o mundo quando se investe nas pessoas e nas relações humanas que surgem e se desenvolvem por meio dessa conexão. Por ela cria-se um espaço propício a mudanças de paradigmas, e apta para desenvolver a criticidade, a interatividade e a colaboração entre os indivíduos.

Desse modo, a tecnologia, por sua capacidade de conectar pessoas, pode contribuir para desenvolver o respeito entre os indivíduos e suscitar profundas reflexões sobre direitos e deveres. Por isso torna-se elemento central na promoção de uma educação participativa e dinâmica, que acompanhe seus processos evolutivos, capazes de levar a todos o sentido de justiça e diversidade. Segundo Candau (2008) é válido:

[...] promover experiências de interação sistemática com os "outros": para sermos capazes de relativizar nossa própria maneira de situar-nos diante do mundo e atribuir-Ihe sentido, é necessário que experimentemos uma intensa interação com diferentes modos de viver e expressar-se. Não se trata de momentos pontuais, mas da capacidade de desenvolver projetos que suponham uma dinâmica sistemática de diálogo e construção conjunta entre diferentes pessoas e/ou grupos de diversas procedências sociais, étnicas, religiosas, culturais etc.

Um dos desafios da pesquisa em direitos humanos é, então, mostrar que é possível uma escola criar no seu espaço, lugar para discussão e diálogo sobre as normas e políticas que permeiam o âmbito escolar. As pessoas que passam por ela são perfeitamente capazes de desenvolver entendimento sobre as políticas educativas e podem estabelecer, com isso, novas diretrizes no campo da educação em direitos humanos. Candau (2008) aponta caminhos para uma escola atual, conectada com sua realidade.

Já na concepção de Ball e Bowe (1992 apud MAINARDES, 2006) a escola é uma arena, em que se concretiza a interpretação das políticas implementadas, em que os atores processam e interagem com novos significados e formam uma nova política, ao realizarem suas próprias interpretações. Para esses autores, os intérpretes (professores e demais profissionais) por terem vivências diferenciadas, não se dão por inocentes, pois quando realizam as interpretações das políticas, agem sobre a política original causando gradações sob diversas dimensões e interesses, justo porque:

[...] os profissionais que atuam no contexto da prática [escolas, por exemplo] não enfrentam os textos políticos como leitores ingênuos, eles vêm com suas histórias, experiências, valores e propósitos [...]. Políticas serão interpretadas diferentemente uma vez que histórias, experiências, valores, propósitos e interesses são diversos. A questão é que os autores dos textos políticos não podem controlar os significados de seus textos. (BALL; BOWE, 1992 apud MAINARDES, 2006, p. 50). 
Pode-se, assim, afirmar que os agentes escolares são indivíduos capazes e necessários para dar efetividade às políticas educacionais, em direitos humanos. A atuação de cada um traz a ressignificação da leitura, outrora feita focada aos textos da lei, rigidamente normatizada de modo que não oportunizava aos indivíduos uma nova interpretação. Devido ao grande potencial humano em atuar sobre as propostas políticas incutidas principalmente nos currículos, novos olhares produzirão leituras de vida, experiências individuais, uma vez que

No âmbito do debate sobre a ressignificação de Direitos Humanos, consideramos produtivo tecer uma abordagem na qual o eixo seja a diferença e não a proposição da igualdade. [...] Uma visão alternativa de Direitos Humanos que assuma como eixo a diferença pode ser constituída pela ótica da heterogeneidade do social e da democracia pluralista, baseada no entendimento de que o conflito que a diferença produz é constitutivo do social e do político. (RAMOS, 2011, p. 196).

Nesse processo, é possível verificar que a ressignificação enfatizada por Ramos (2011) se constitui na construção de ideias que definam as políticas relativas às diferenças e à diversidade. Dias e Lopez (2006, p. 56) afirmam que os textos curriculares se constituem em "[...] temas híbridos marcados pelas mesclas de diferentes marcas e perspectivas favorecendo a convergência/transferência de políticas e a heterogeneidade das políticas.". Sendo assim, a concretização democrática de uma política articulada, deve ser composta pelas diversidades e complexidades humanas. Repleta de desafios, mas nutrida pela liberdade de pensar com todos os que se comprometem com a transformação da sociedade. O que significa transformar uma cultura solidificada, que observa as pessoas como seres incapazes de realizar mudanças em suas ações. A prática educativa deve assumir a realização da igualdade nas diferentes formas de ser do indivíduo, e as políticas educacionais articuladas aos ideais de respeito e cidadania ajudarão os seus agentes a refletirem sobre o cotidiano escolar e a aceitarem os desafios que dele decorrem.

Nesse sentido, Candau (2008) entende que as ações em direitos humanos devem considerar a dinâmica de projetos que visem ser construídos por meio do diálogo entre pessoas que englobam as variadas raças, religiões e etnias. Acima de tudo, o comprometimento com a transformação deve se concretizar a partir de novas práticas e na construção das identidades culturais. Para a autora: "Trata-se de um enfoque global que deve afetar todos os atores e todas as dimensões do processo educativo, assim como os diferentes âmbitos em que ele se desenvolve" (CANDAU, 2008, p. 54).

Pode ser interessante, se empenhar em sondar e analisar o interior da escola para avaliar a dinâmica do contexto social e as relações entre os sujeitos nela envolvidos. Entender o porquê da ineficácia de algum projeto escolar sobre direitos humanos e a resistência para transformação proposta pelas Diretrizes educacionais. Facci (2019, p. 132) afirma ser necessário considerar a vida social dos atores, compreendendo o entorno na qual se inserem, ou seja, perceber:

Condições objetivas como falta de investimento financeiro para a educação, precarização do trabalho, baixos salários, formação inicial de baixa qualidade, falta de políticas educacionais direcionadas à formação continuada dos professores, falta de estrutura física adequada para a atividade pedagógica.

Uma diretriz educacional importante consiste na transformação que está relacionada a fazer com que o sujeito possa realizar uma nova interpretação de sua existência, em um universo onde saiba lidar com violações e preconceitos e transcender. Transcender para uma educação em que a principal esperança é contribuir e alterar o curso sobre o sentido de humanidade (BRASIL, 2007).

É evidente que a escola vive a angústia de muitas vezes estar inserida em um ambiente de violência e de intolerância, sobretudo quando não promove ações eficazes 
com o intuito de pelo menos, minorá-los. É preciso, então, despertá-la, trazendo-a à reflexão sobre o seu papel dentro da sociedade, trabalhando para que todos os envolvidos participem coletivamente da formação dos projetos, estabelecendo uma interrelação entre as propostas da comunidade e as da escola. Mas, para despertar a escola, talvez despertar o educador seja o caminho. De acordo com Alves (1994, p. 37),

Não sei como preparar o educador. Talvez porque isso não seja necessário, nem possível.... É necessário acordá-lo [...]. Basta que os chamemos do seu sono, por um ato de amor e coragem. E talvez, acordados, repetirão o milagre da instauração de novos mundos.

Um dos principais compromissos da educação em direitos humanos é inserir no aprendizado diário dos alunos, professores e demais agentes escolares, a valorização e o respeito entre os indivíduos. Um dos caminhos pode ser a formulação de projetos digitais que ajudem a transformar a exclusão social e a vivência da violência, que se dá nas mais variadas formas: velada, explicita, implícita e midiática. A escola não deve negligenciar a sua função de mediar conflitos, descobrindo possibilidades para amenizar ou dissipar tais tensões.

A educação constitui-se assim, como espaço dos mais relevantes e legítimos para a construção desses "novos mundos" e, para consolidação de seus objetivos, é preciso haver a comunhão de todos os indivíduos, com suas ideias, justamente por serem multiculturais e diversificadas. Nessa perspectiva é possível haver uma real mudança individual e coletiva, que vise educar em direitos humanos para multiplicar sujeitos mais humanos. É nesse sentido que a escola se constrói, buscando estratégias que viabilizem:

A formação de cidadãos (ãs) conscientes de seus direitos e deveres, protagonistas da materialidade das normas e pactos que os (as) protegem, reconhecendo o princípio normativo da dignidade humana, englobando a solidariedade internacional e o compromisso com outros povos e nações. Além disso, propõe a formação de cada cidadão (ã) como sujeito de direitos, capaz de exercitar o controle democrático das ações do Estado. (BRASIL, 2007, p.23).

O papel articulador de mudanças na direção de uma educação atenta aos direitos humanos não é uma função fácil de a escola desempenhar, mas criatividade e atitude são necessárias e indispensáveis nestes tempos difíceis e conturbados. É preciso inovar e acompanhar as dinâmicas sociais e os mecanismos que façam a escola transpor os seus desafios. O meio digital, as mídias estão à disposição, basta que se promovam no chão da escola oportunidades em adentrar esse espaço repleto de possibilidades.

\subsection{Educação, Direitos Humanos e Novas Tecnologias}

Os hipertextos são considerados variações de textos (multimodalidade) que são representados em múltiplas funções que a linguagem pode oferecer. As páginas dos hipertextos podem ser constituídas de variados formatos de apresentação (cores, sons e imagens) além de serem representativos, pois podem sugerir, por sua dinâmica, a atuação daqueles que os manuseiam ou agem em função ou por meio dele. Para Oliveira (2015):

As tecnologias vêm influenciando a forma como as pessoas têm interagido com o mundo que as cercam e os avanços tecnológicos vêm tornando as formas de comunicação mais rápidas e multimodais. [...] E essas características têm se refletido nos textos, que se tornaram cada vez mais multissemióticos, ou seja, formados por linguagens variadas, constituídos por palavras, imagens, cores, sons, gestos, entre outros, que se integram na constituição do sentido. As mudanças ocorridas nos textos geraram a necessidade da realização de novos estudos a respeito dos elementos multissemióticos que estão constituindo a comunicação na sociedade atual. Trabalhar com a compreensão leitora como uma atividade social e dinâmica implica ressaltar o caráter multifacetado da leitura, só assim, é possível 
reformular práticas e comportamentos realizados dentro da escola e assumir seu papel social.

Por essa afirmação, tem-se que a escola conectada poderá com essa modalidade de mídia criar páginas de acesso aos estudos da realidade local, incentivando os alunos a serem pesquisadores de suas necessidades sejam sociais, econômicas, políticas. Os alunos poderão ser protagonistas de novas criações para o exercício da cidadania e voltadas aos direitos humanos, formar frentes de captação de doações, promover encontros (palestras, mesas redondas, cinema projetado), conectando setores políticos, jurídico e escolar com fim de encontrar caminhos para melhoria da vida na escola e fora dela, por intermédio do hipertexto. Segundo Verdan (2011):

[...] Os hipertextos sejam on-line ou offline são informações textuais combinadas com imagens, sons, organizadas de forma a promover uma leitura (ou navegação) não-linear, baseada em indexações e associações de ideais e conceitos, sob a forma de links. Os links funcionam como portas virtuais que abrem caminhos para outras informações. O hipertexto é uma obra com várias entradas, onde o leitor/navegador escolhe seu percurso pelos links.

As novas tecnologias possibilitam a inclusão de uma diversidade de grupos na sociedade, possibilitando a formação de um espaço cibernético universal que pode elevar o ser humano ao seu potencial imaginativo. Isso quer dizer que sendo a pessoa conduzida nesse ciberespaço, sentir-se-á tão encorajada quanto qualquer outro que nele atua, basta que para isso seja conduzido de forma orientada e produtiva (LÉVY, 1999). Por isso, a escola é essencial, pois na junção entre os saberes, todos podem aprender uns com os outros, pois em cada porção de saber pode se compartilhar o caráter e o respeito à diversidade.

Dentro dessa lógica, o que temos são pessoas que fazem uso, pensam e dão sentido às máquinas, quando se colocam esforços diversos em ajudar, orientar e criticar positivamente. A construção da cidadania está ligada ao desenvolvimento de relações edificantes no que respeita os direitos e deveres dos cidadãos. E tal construção pode estar presente quando as pessoas usam o WhatsApp ou Facebook para organizar uma manifestação, encontros e eventos em função de algum órgão ou pessoa individualmente. As mentes se unem, as forças se juntam e se têm resultados positivos com a união das inteligências, que formam uma inteligência coletiva. Lévy (1999, p. 29) expõe que:

O ciberespaço como suporte da inteligência coletiva é uma das principais condições de seu desenvolvimento. Toda a história da cibercultura testemunha largamente sobre esse processo de retroação positiva, ou seja, sobre a automanutenção da revolução das redes digitais.

Para Santos (2014) a cibercultura representa a cultura contemporânea, em que a comunicação, a produção e a circulação em rede de informações e conhecimentos ocorrem na interface cidade-ciberespaço, fazendo emergir novos arranjos espaçotemporais e, que possibilitam novas práticas educativas e de formação.

O que se pode depreender é que são as inteligências humanas e individuais que fornecem vida ao espaço digital, interligadas a outras várias formas de inteligências, que darão suporte a outras criações. Portanto, é crível entender por que é possível associá-la aos espaços educativos, em que as diferenças podem convergir para a criatividade em vários campos de saber. Lévy (1999, p. 30) ainda ressalta que:

[...] devido a seu aspecto participativo, socializante, descompartimentalizante, emancipador, a inteligência coletiva proposta pela cibercultura constitui um dos melhores remédios para o ritmo desestabilizante, por vezes excludente, da mutação técnica. [...] é um remédio para aqueles que mergulham em seus turbilhões e conseguem controlar a própria deriva no meio de suas correntes. 
Nessa esteira de interpretações sobre a cibercultura, pode-se integrar a educação em direitos humanos, mergulhando nesse espaço dinâmico e criativo ao que os autores se referem. $\mathrm{O}$ universo de habilidades humanas ao se conectarem e interagirem no espaço cibernético, vão se integrando e se atualizando em um "ciclo positivo de alteração" (LÉVY, 1999, p. 30). Essa mutação técnica apropriada pelos indivíduos, acaba por democratizar a informação e incluir a todos que participam desse dinamismo informacional.

Quem um dia imaginou poder se comunicar com outras pessoas de países distantes ou, pelo telefone celular, poder divulgar algum trabalho, desenvolver planejamentos, compartilhar serviços, ideias e imagens? Muitos adultos, às vezes, precisam de orientação para manipular os aplicativos, entretanto, quanto às crianças e adolescentes, ninguém se dispõe a ensiná-las a abrir uma página, um vídeo ou uma imagem, porque já aprendem por elas mesmas, pela curiosidade e experimentação, com erros e acertos. Por isso é válido considerar o uso das tecnologias na escola como modo um dinâmico e enriquecedor para o ensino e aprendizagem, com games, páginas interativas, vídeos, entre outros.

Um exemplo utilizado por muitos professores é o Facebook, ferramenta digital que neste momento tem se mostrado como possibilidade de desenvolvimento da aprendizagem, comunicação e difusão de trabalhos e atividades de forma geral. LUNARDON (2013, p. 27) argumenta que,

[...] o Facebook por se configurar como uma rede que permite a interação entre os usuários e também a disponibilização de arquivos ou mídias específicas, pode ser um grande aliado ao trabalho pedagógico [...]. Ao analisar esta rede social, é possível constatar a existência de uma série de recursos ou tipos de ações, como: imagens; textos; vídeos; links; produção de enquetes; envio de mensagens; produção de festas; criação de grupos diversos. Tudo isso em uma única interface, concentrado em uma única página web, de maneira que o uso das ferramentas se torne extremamente intuitivo.

Assim, por seu potencial de compartilhamento de imagens e textos, alunos e professores podem trocar opiniões, que dizem respeito à política, esporte, economia, e desenvolver formas mais dialógicas de contestar, discordar e divulgar notícias. A ferramenta pode ajudar a potencializar a aptidão para escrita e leitura.

Existem várias modalidades de aplicativos oferecidos pela tecnologia digital que podem ser explorados com o intuito de demonstrar sua função e aplicabilidade no âmbito educacionali. No entanto, este artigo se detém na observação de uma bibliografia que discute os desafios de uma educação conectada aos direitos humanos e às novas tecnologias.

\subsection{Escolas, Novas Tecnologias e Direitos Humanos}

Percorrendo as páginas na web nota-se que há poucos planos de ações inteiramente voltados ao trabalho de educação em direitos humanos e novas tecnologias. O que se têm são oficinas de formação, propostas feitas para inclusão de uma determinada minoria, com ações isoladas, que não garantem a continuidade e permanência dessas a práticas em níveis institucionaisii.

Além disso, ao refletir sobre educação em direitos humanos e novas tecnologias, se observa a realidade do aparelhamento tecnológico precário das escolas, pois ainda que haja investimento para aparelhar as escolas, com computadores e tablets, por exemplo, a pesquisa de Paiva (2010) apontou para a carência estrutural de várias escolas em Minas Gerais, que servem de espelho para que se observem as escolas brasileiras, sem infraestrutura mínima de funcionamento para o uso e manutenção das tecnologias informacionais. Isso nos remete à precária utilização dos recursos tecnológicos, 
especialmente os digitais, nas salas de aula do ensino fundamental, nas escolas públicas (PADILHA; ABRANCHES, 2010).

Os professores nem sempre recebem formação para usar pedagogicamente os recursos digitais. Por vezes, acontecem atividades esporádicas de alguns professores, ou seja, práticas isoladas com o uso das tecnologias digitais na sala de aula, que carecem de uma maior integração entre os docentes não somente na própria escola, mas na rede pública de um modo geral (OLIVEIRA, 2018).

Padilha e Abranches (2013) afirmam que os professores do ensino fundamental percebem a utilidade da tecnologia no seu cotidiano, bem como seu caráter inovador, e a importância de usá-la na sala de aula pelo seu poder motivacional. Porém, os autores ressaltam que no momento de planejar as aprendizagens de seus alunos com essas tecnologias, os professores, em geral, assumem uma prática tradicional.

Carreira (2014) no curso de Educação, Direitos Humanos e Tecnologias, em sua aula de abertura faz menção à historicidade sobre a negação do uso das tecnologias pelas mulheres e indígenas. Por outro lado, aborda as oportunidades que a educação e as políticas públicas envolvidas em direitos humanos e a tecnologia podem trazer ao indivíduo, além de entender que:

As tecnologias provocam a educação a se repensar e podem sim provocar a quebra dos muitos muros das escolas, ampliar o leque de possibilidades de trajetos formativos dos sujeitos, estimular um papel mais ativo e autoral de educadores e estudantes, valorizando produções colaborativas, estimulando sujeitos coletivos e produções contextualizadas nas realidades locais. Contribuindo para fortalecer uma perspectiva política de currículo mais sintonizada com os interesses, necessidades e demandas das pessoas, coletivos e comunidades concretas.

A abordagem feita por Silva, Marques e Donadel (2013, p. 8-9) sobre o tema Direitos Humanos e Educação novas tecnologias, encontra-se no artigo denominado "Inclusão digital e direitos humanos: desafio à educação contemporânea". Eles reforçam que a inclusão digital deve abranger a sociedade oferecendo aos indivíduos a oportunidade de se transformar para transformar o universo no qual vive, visto que, segundo eles:

A educação é o meio pelo qual, com informação e direitos humanos, podem-se incluir os excluídos, reduzindo assim as desigualdades sociais". [...]Por meio da inclusão digital na escola alunos e educadores trazem à tona os problemas que mais afetam a coletividade e mesmo suas vidas, buscando utilizar a tecnologia como meio de exercício do direito de cidadania.

O uso da tecnologia talvez possa abrir novos campos para o enfrentamento de questões relacionadas aos direitos humanos e à cidadania, como a inclusão social e o respeito ao multiculturalismo.

\section{METODOLOGIA}

A metodologia utilizada nesta pesquisa é qualitativa e considerou como estratégia a elaboração de uma revisão bibliográfica, buscando autores que trouxessem conceitos sobre os direitos humanos e sobre como as novas tecnologias poderiam aproximar as crianças e os jovens deste debate, principalmente nas escolas. Debate este relevante nos tempos atuais, onde uma formação voltada para a cidadania deve ser buscada.

\section{CONSIDERAÇÕES FINAIS}

Tratar dos direitos humanos no âmbito escolar torna-se essencial para promoção de uma reflexão consciente dos indivíduos sobre bullying, cyberbullying, desigualdades sociais, sexualidade e multiculturalismo, o que possibilitará o acesso a novas concepções 
de direitos e deveres que cada um deve exercer. Por isso a escola é tão importante, pois é o espaço propício ao desenvolvimento do respeito e da prática desses direitos e de sua manutenção.

Para que se construa o real sentido de cidadania e se estabeleça o Estado de direito e respeito mútuo entre os seres humanos, as instituições, junto à sociedade, devem propor pautas que incluam a educação relacionada aos direitos humanos. Diante disso, ter como fio condutor as novas tecnologias pode ser um caminho, no intuito de conhecer e explorar a diversidade e transformar democraticamente estudantes em cidadãos.

Talvez a contribuição deste artigo seja mais no sentido de propor questões. Isso porque ainda há um longo caminho a percorrer para se relacionar educação e direitos humanos a partir do uso das novas tecnologias. Se por um lado, as novas tecnologias diminuem as distâncias entre os indivíduos e podem fazer com se conheçam e se reconheçam, por outro, somente através do contato, ainda que virtual, podem ser desenvolvidas noções de direitos humanos. O desafio está posto para aqueles que desejam uma educação mais inclusiva e humanizadora, integrada aos novos tempos, que incluem as tecnologias digitais.

\section{REFERÊNCIAS}

ALVES, Rubem. Conversas com quem gosta de ensinar: (+) qualidade total na educação. 10.ed., Campinas: Papirus, 2008.

ASSEMBLEIA GERAL DA ONU. (1948). Declaração Universal dos Direitos Humanos (217 [III] A). Paris. Disponível em: <https://www.un.org/en/universal-declaration-humanrights/>. Acesso em: 09 jun. 2020.

BALL, S.J.; BOWE, R. Subject departments and the "implementation" of National Curriculum policy: an overview of the issues. Journal of Curriculum Studies, London, v. 24, n. 2, p. 97-115, 1992.

BRASIL. Comitê Nacional de Educação em Direitos Humanos. Plano Nacional de Educação em Direitos Humanos/Comitê Nacional de Educação em Direitos Humanos. - Brasília: Secretaria Especial dos Direitos Humanos, Ministério da Educação, Ministério da Justiça, UNESCO, 2007. 76 p. 24 fev. 20. Disponível em: < http://portal.mec.gov.br/docman/2191-plano-nacional-pdf/file>. Acesso em: 20 mar. 2020.

BRASIL. Constituição da República Federativa do Brasil. Brasília, DF: Senado Federal: Centro Gráfico, 1988, 292 p.

BRASIL. Estatuto de Roma do Tribunal Penal Internacional - Planalto. Disponível em: <http://www.planalto.gov.br/ccivil_03/decreto/2002/d4388.htm> decreto. Acesso em: 17 mar. 2020.

BRASIL. Ministério da Educação. Secretaria de Educação Fundamental. Parâmetros curriculares nacionais: apresentação dos temas transversais, ética. Secretaria de Educação Fundamental. - Brasília: MEC/SEF, 1997. 146p. Disponível em: http://portal.mec.gov.br/seb/arquivos/pdf/livro081.pdf. Acesso em: 04 abr. 2020. BRASIL. Secretaria de direitos humanos da presidência da república. Educação em direitos humanos: diretrizes nacionais. Brasília: Coordenação geral de educação em $\mathrm{sdh} / \mathrm{pr}$, diretoria de direitos humanos, secretaria nacional de promoção e defesa de dh, 2013. Disponível em: < http://portal.mec.gov.br/index.php?option=com_docman\&view=download\&alias=32131 educacao-dh-diretrizesnacionais-pdf\&ltemid=30192 >. Acesso em: 03 mar. 2020. 
CANDAU, V. M.; SACAVINO, S. (Orgs.). Educação em direitos humanos: temas, questões e propostas". Rio de Janeiro: DP \& ALLI, 2008.

CANDAU, V. M. Direitos Humanos, educação e interculturalidade: as tensões entre igualdade e diferença. Revista Brasileira de Educação, v. 13, n. 37, p. 45-56, jan a abr. 2008. Educação em Direitos Humanos: Disponível em: <https://www.scielo.br/pdf/rbedu/v13n37/05.pdf>. Acesso em: 03 abr. 2020. CARVALHO, J. S. F. de. Educação e Direitos Humanos: formação de professores e práticas escolares. Ética e cidadania. Boletim, 18, out. 2006. Disponível em: < http://www.dhnet.org.br/dados/cursos/edh/redh/01/salto_etica_e_cidadania.pdf. Acesso em: 04 abr. 2020.

CARREIRA, D. Educação, direitos humanos e tecnologia: questão em jogo. Portal Geledés Instituto da mulher negra. 22 ago. 2014. Disponível em: $<$ https://www.geledes.org.br/educacao-direitos-humanos-e-tecnologia-questoes-emjogo/>. Acesso em: 04 mar. 2020.

DIAS, R. E.; LÓPEZ, S. B. Conhecimento, interesse e poder na produção de políticas curriculares. Currículo sem fronteiras, v. 6, n. 2, p. 53-66, jul a dez. 2006. Disponível em: <http://www.curriculosemfronteiras.org/vol6iss2articles/dias-lopez.pdf> Acesso em: 03 abr. 2020

ENCICLOPÉDIA DO HOLOCAUSTO. Introdução ao Holocausto. Disponível em: $<$ https://encyclopedia.ushmm.org/content/pt-br/article/introduction-to-the-holocaust> .Acesso em: 9 abr. 2020.

FACCI, M. G. D. O adoecimento do professor frente à violência na escola. Fractal Revista de Psicologia, Rio de Janeiro, v.31, n.2, p. 130-142, mai a ago. 2019. Disponível em: <http://www.scielo.br/scielo.php?script=sci_arttext\&pid=S198402922019000200130\&lng=en\&nrm=iso >. Acesso em: 04 abr. 2020.

LÉVY, P. Cibercultura. São Paulo: Editora 34, 1999.

LUNARDON, E. A. D. O Uso do Facebook no processo de ensino-aprendizagem de leitura e escrita de textos argumentativos. Curitiba, 2013. Cadernos PDE, v.2. Disponível em:<http://www.diaadiaeducacao.pr.gov.br/portals/cadernospde/pdebusca/producoes_pde /2013/2013_utfpr_port_pdp_eliane_aparecida_dias.pdf >. Acesso em: 01 jun. 2020.

MAINARDES, J. Abordagem do ciclo de políticas: uma contribuição para a análise de políticas educacionais. Revista Educação \& Sociedade, Campinas, v. 27, n. 94, p. 4769, jan a abr. 2006. Disponível em:

<https://www.scielo.br/pdf/es/v27n94/a03v27n94.pdf>. Acesso em: 03 mar. 2020.

OLIVEIRA, M. N. de. Multimodalidade e leitura crítica: novas perspectivas para o ensino de Língua Portuguesa. Pensares em Revista, São Gonçalo, n. 6, p. 145-162, jan a jun. 2015. Disponível em:<https://www.e-

publicacoes.uerj.br/index.php/pensaresemrevista/article/view/17192>. Acesso em: 24 fev. 2020.

OLIVEIRA, S. G. de. As Tecnologias Educacionais na Formação de Professores: Uma Mudança de Paradigma. 122 p. 2018. Dissertação de (Mestrado Profissional em Novas Tecnologias Digitais na Educação) - Centro Universitário Carioca, Rio de Janeiro. Disponível em: <https://proximal.unicarioca.edu.br/portal/as-tecnologias-educacionais-naformacao-de-professores-uma-mudanca-de-paradigma/>. Acesso em: 07mai. 2020

PADILHA, M. A. S. Relatório de Projeto de Extensão: pesquisando e aprendendo sobre o uso das tecnologias da informação e comunicação como recurso didático-pedagógico para o ensino nas escolas da rede pública de ensino fundamental e médio. Pernambuco :PROEXT: Universidade Federal de Pernambuco, 2010. 
PADILHA, M. A. S. Inclusão digital como direito humano: a escola, seus sujeitos, seus direitos. Debates em Educação, v. 10, n. 22, p. 191-204, 2018. Disponível em: <http://www.seer.ufal.br/index.php/debateseducacao/article/view/5316>. Acesso em: 17 abr. 2020.

PADILHA, M. A. S.; ABRANCHES, S. P. Relatório de Formação Continuada na Rede Municipal de Camaragibe: Rede Nacional de Formação de Professores da Educação Básica - Renafor. Recife: Universidade Federal de Pernambuco.

PAIVA, L. L. de. Do giz colorido ao data show: uma conexão desconectada. Juiz de Fora: UFJF, 2010.

PRAZERES, M. 7 componentes para entender as relações entre tecnologias e educação. São Paulo: Ação Educativa, 2014. Disponível em:< http// file:///C:/Users/veron/Downloads/7_componentes_para_entender_as_rela\%C3\%A7\%C3\% B5es_entre_a_educa\%C3\%A7\%C3\%A3o_e_as_tecnologias.pdf $>$. Acesso em: $01 \mathrm{abr}$. 2020.

RAMOS, A. H. Educação em Direitos Humanos: local da diferença. In: Revista Brasileira de Educação, v. 16, n. 46, jan a abr., 2011. Disponível em:

<https://www.scielo.br/pdf/rbedu/v16n46/v16n46a11.pdf>. Acesso em: 16 mar. 2020. SANTOS, E. Pesquisa-formação na Cibercultura. Santo Tirso, Portugal: Whitebooks, 2014.

SILVA, G. C. e. Tecnologia, educação e tecnocentrismo: as contribuições de Álvaro Vieira Pinto. Revista brasileira de estudos pedagógicos, Brasília, v. 94, n. 238, p. 839-857, set a dez 2013. Disponível em: <http://www.scielo.br/pdf/rbeped/v94n238/a10v94n238.pdf>. Acesso em: 31 mar. 2020. SILVA, R.; MARQUES, A. D.; DONADEL, M. V. S. Inclusão digital e Direitos Humanos: desafio à educação contemporânea. In: EDUCOM SUL,2, 2013, ljuí/RS. Anais ... ljuí/RS, 2013, p. 1-11. Disponível em: <http://coral.ufsm.br/educomsul/2013/com/gt2/12.pdf>. Acesso em: 06 jun. 2020.

SOUZA, I. O que são direitos humanos? Politize, abr. 2017. Disponível em: <https://www.politize.com.br/direitos-humanos-o-que-sao/>. Acesso em: 09 jun. 2020. VERDIN. R. O que é Hipertexto? Web artigos, 16 apr., 2011. Disponível em: < https://www.webartigos.com/artigos/o-que-e-hipertexto/63870>. Acesso em: 24 fev. 2020. VILAÇA, M. L. C.; ARAÚJO, E. V. F. de. Tecnologia, sociedade e educação na era digital. Duque de Caxias: UNIGRANRIO, 2016. [Livro eletrônico]. Disponível em: < http://www.pgcl.uenf.br/arquivos/tecnologia,sociedadeeeducacaonaeradigital_0111201815 54.pdf>. Acesso em: 01 jun. 2020.

\footnotetext{
' A título de ilustração há várias dissertação sobre o uso de aplicativos na educação, como: O Uso do aplicativo Instagram e da câmera do celular como ferramentas de aprendizagem na atividade de projeto fotografando meu bairro (2019), de Adriano B. L. da Silva; Aplicativos Móveis em Sala de Aula: Uso e Possibilidades para o Ensino da Matemática na EJA (2018), de Werbert A. Coutinho e Pequenos Conteúdos por Mensagens Instantâneas como Recurso de Aprendizagem (2019) por Geraldo L. J. S. Lopes. Os trabalhos podem ser encontrados em: https://proximal.unicarioca.edu.br/portal/dissertacoes/ Acesso em: 08 jun. 2020.

ii O livro "Educação em direitos humanos: temas, questões e propostas", organizado por Candau e Sacavino (2008), traz algumas práticas docentes na direção da educação e os direitos humanos nas escolas, além de apresentar também iniciativas de formação de professores no mesmo sentido, como o Novamérica, rede de pesquisadores que formam professores com relação aos direitos humanos, promovendo o programa Diretos humanos, Educação e Cidadania.
} 